\title{
Two Level Control Strategy for Independent AC/DC Hybrid Microgrid Based on Integrated Control
}

\author{
Hanmin Liu ${ }^{1}$, Zhenyu Wang ${ }^{2,3 *}$, Shouxiang Wang ${ }^{2,3}$, Qi Liu ${ }^{2,3}$, Guozhong Zhang ${ }^{1}$, Yunfeng Tian ${ }^{1}$, Yu Shen ${ }^{1}$ and Qianyu \\ Zhao ${ }^{2,3}$ \\ ${ }^{1}$ Wind and Solar Power Energy Storage Demonstration Station Co., Ltd State Grid, Hebei Province Wind and Solar Energy storage \\ Combined Power Generation Technology Innovation Centre, Zhangjiakou City, 075000, China \\ ${ }^{2}$ Key Laboratory of Smart Grid of Ministry of Education, Tianjin University, Tianjin 300072, China \\ ${ }^{3}$ Key Laboratory of Power System Simulation and Control, Tianjin University, Tianjin 300072, China
}

\begin{abstract}
Aiming at the independent AC/DC microgrid, a simple and effective multi time scale control strategy is proposed by adopting the combination of day ahead scheduling and real-time control. The day ahead scheduling strategy takes the minimum operation cost of $\mathrm{AC} / \mathrm{DC}$ microgrid as the goal, and schedules the controllable loads in the AC/DC microgrid with particle swarm optimization, which makes full use of renewable energy. The real-time control strategy controls the output of the distributed generation, the load reduction and the switching of the diesel generator according to the real-time energy storage state of charge (SOC), which keep the power balance of the AC/DC microgrid. The effectiveness of the proposed two-level control strategy is verified by a practical AC/DC hybrid microgrid. The results show that the proposed method can make full use of renewable energy and ensure the economic and reliable operation of AC/DC hybrid microgrid.
\end{abstract}

\section{Introduction}

The microgrid composed of photovoltaic, energy storage, diesel generator and other equipment has the advantages of making full use of renewable energy and providing independent power supply for users, which is suitable for supplying power to users in areas where the construction of power facilities is difficult, such as islands and mountainous areas ${ }^{[1,2]}$. Compared with the traditional single AC microgrid or DC microgrid, AC/DC hybrid microgrid has the advantages of convenient DC load access, high acceptance capacity of distributed generation, flexible and diverse networking form and control mode ${ }^{[3]}$, which can improve the level of system security and stability and reduce network loss ${ }^{[4,5]}$.

As one of the core technologies of microgrid, optimal dispatch is an important support to deal with the uncertainty of renewable energy and load and ensure the economic and reliable operation of microgrid ${ }^{[6,7]}$. Compared with the traditional $\mathrm{AC}$ microgrid, AC/DC hybrid microgrid presents the characteristics of $\mathrm{AC} / \mathrm{DC}$ operation zoning, energy coupling, source load variety and operation mode diversification ${ }^{[8-10]}$, so the optimal dispatching of $\mathrm{AC} / \mathrm{DC}$ hybrid microgrid is more complex.

At present, domestic and foreign scholars have done some research on the optimal dispatching of $\mathrm{AC} / \mathrm{DC}$ hybrid microgrid. In reference [11], considering the operation cost, fuel emission and power loss load of microgrid, the optimization objective function is established and solved by multi-objective particle swarm optimization algorithm. According to document [12], a method combining daily dispatching with day scheduling is proposed for the operation optimization of microgrid containing sodium-sulfur battery energy storage system. The real-time scheduling plan is based on ultra-shortterm power forecasting, which can modify the day ahead dispatching plan to ensure the optimal operation of the microgrid. In reference [13], the island independent microgrid system adopts the method of time-to-time control, and the system scheduling strategy is formulated with the constraints of system active power balance and normal operation of equipment. In reference [14], according to the load characteristics of AC/DC hybrid microgrid in practical application, the microgrid optimal dispatching plan is formulated, and the economy and power supply reliability of microgrid are improved with the help of demand side management technology.

This paper proposes a multi time scale power regulation strategy for island independent $\mathrm{AC} / \mathrm{DC}$ hybrid microgrid. A micro grid power regulation strategy combining daily dispatching and real-time control is adopted. The day ahead scheduling strategy aims at minimizing the cost of operation, and establishes a mathematical model using particle swarm algorithm to solve the problem. It distributes the adjustable load size and the power consumption time to provide a reference for the island electricity arrangement. The real-time control strategy controls the output of distributed generation, the reduction of load and the switching of

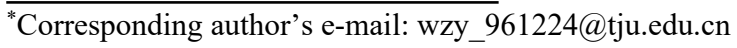


diesel generator according to the real-time energy storage SOC. The proposed method is simple and reliable, and can effectively use renewable energy to generate electricity, ensuring the economic and reliable operation of $\mathrm{AC} / \mathrm{DC}$ hybrid microgrid.

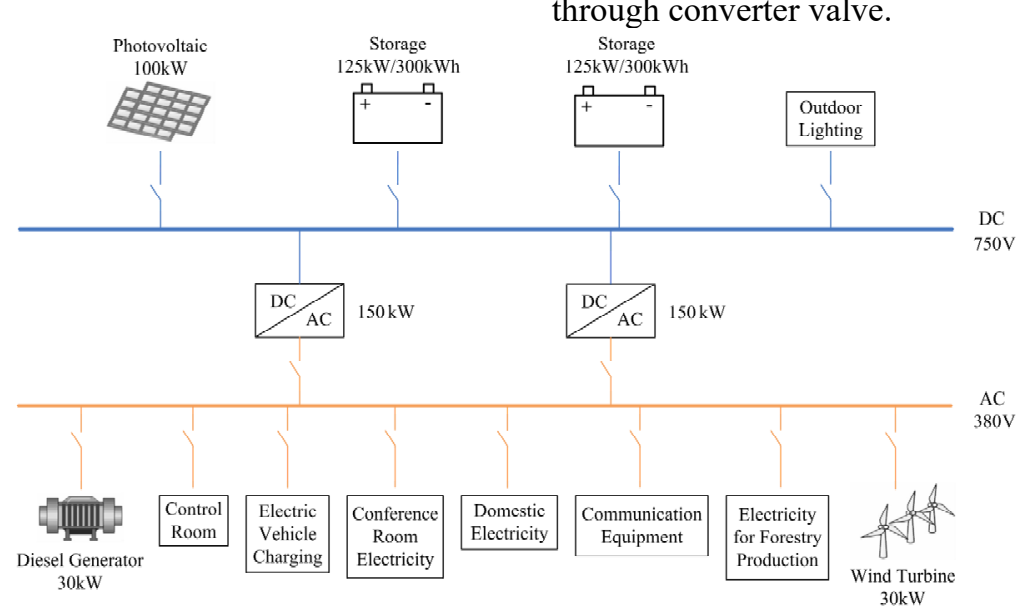

Figure 1 Topology of island AC/DC hybrid microgrid

\subsection{Load Model}

According to the load characteristics and power supply load, reducible load, translatable load and flexible load.

- Fixed Load: This type of load cannot be regulated by the power system, cannot be reduced or shifted, and its demand must be met. or decrease the power consumption within a certain period of time according to the needs of system regulation. requirements, it can be divided into four categories: fixed

- $\quad$ Reducible Load: This type of load can increase

\section{Independent AC/DC Hybrid Microgrid}

\subsection{Topology of Independent AC/DC Hybrid Microgrid}

Figure 1 shows the topology of an independent AC/DC hybrid microgrid in a mountainous area. Photovoltaic and wind turbine are the main power sources of microgrid. The energy storage system maintains DC voltage, and the $\mathrm{AC}$ system maintains $\mathrm{AC}$ voltage through converter valve.

$125 \mathrm{~kW} / 300 \mathrm{~kW}$

$30 \mathrm{~kW}$
- Translatable Load: This type of load can be transferred according to the needs of system regulation and control, but it must be completed within a certain time.

- Flexible Load: This type of load belongs to non-essential load, its power consumption and power consumption period can be adjusted according to the needs of system regulation, and can be stopped when necessary.

The load size and load type are shown in Table $\mathbf{1 .}$

Table 1 The characteristics of island load

\begin{tabular}{ccc}
\hline Load name & Load size & Load type \\
\hline Class I domestic electricity & $10 \mathrm{~kW}$ & Reducible load \\
Class II domestic electricity & $4 \mathrm{~kW}$ & Translatable load \\
Class III domestic electricity & $3 \mathrm{~kW}$ & Fixed load \\
Communication equipment & $6 \mathrm{~kW}$ & Fixed load \\
Electricity for forestry production & $20 \mathrm{~kW}$ & Translatable load \\
Outdoor lighting & $10 \mathrm{~kW}$ & Fixed load \\
Control room & $15 \mathrm{~kW}$ & Fixed load \\
Electric vehicle charging & $10 \mathrm{~kW}$ & Translatable load \\
Conference room electricity & $15 \mathrm{~kW}$ & Flexible load \\
\hline
\end{tabular}

(6:00-18:00); the translatable period of electric vehicle

Among them, Class I domestic electricity mainly includes: air conditioners, induction cookers, rice cookers, and boiling water cookers; Class II domestic electricity mainly includes: washing machines and bath heaters; Class III domestic electricity mainly includes: electricity for lighting and refrigerators. The translatable period of class II domestic electricity is $(6: 00-22: 00)$; the translatable period of forestry production electricity is charging is (0:00-24:00), but it needs to run for at least 12 hours every day. 


\section{Control Strategy of AC/DC Hybrid Microgrid}

AC/DC hybrid microgrid uses new energy to the maximum extent, reduces the operation time of diesel generator as far as possible, and improves the economy and environmental protection of the system. Considering the shortage of personnel allocation in mountainous areas, it is difficult to provide special micro electricity network management and control personnel. Therefore, the control strategy combining daily dispatching strategy with real-time control is adopted. The day ahead scheduling strategy provides a reference for the electricity arrangement, assigns the size of the adjustable load and the power consumption time. The real-time control strategy controls the switching of the distributed power through energy storage SOC.

\subsection{Day Ahead Scheduling Strategy}

Taking $\Delta t=15 \mathrm{~min}$ as a scheduling cycle, the objective function can be expressed as:

$$
\min f_{\text {cost }}=N_{G} k_{G_{-} o n}+\sum_{t=1}^{N_{\text {dav }}}\left(P_{G}(t) k_{G_{-} \text {ope }}+P_{\text {lost }}(t) k_{\text {lost }}\right) \Delta t
$$

where, $f_{\text {cost }}$ is the total operating cost of the system in one day; $N_{G}$ is the starting times of the diesel generator in one day; $k_{G \text { on }}$ is the starting cost of the diesel generator each time, which is taken as 100 yuan/time in this paper; $P_{G}(t)$ is the generating power of the diesel generator in period $t ; k_{G_{-} \text {ope }}$ is the generating cost of the diesel generator, which is taken as 0.4 yuan $/ \mathrm{kW}$ in this paper; $P_{\text {lost }}(t)$ is the loss of load in period $t ; k_{\text {lost }}$ is the loss of load cost, which is taken as 0.8 yuan $/ \mathrm{kW}$ in this paper.

Considering the small scale of microgrid, the transmission capacity constraints of converter valve and transmission line can be satisfied in design, and the system voltage is regulated by energy storage, so the voltage constraint can be converted into energy storage SOC constraint. Therefore, the constraints of day ahead scheduling include the power balance constraint of microgrid and the upper and lower limit of energy storage SOC.

The power balance constraints of microgrid can be expressed as:

$$
P_{G}+P_{e s s}+P_{W T}+P_{P V}=P_{\text {load }}
$$

where, $P_{e s s}$ is the charging and discharging power of energy storage (positive power means discharging, negative power means charging), and $P_{\text {load }}$ is the load power.

The power and capacity constraints of energy storage can be expressed as follows:

$$
\begin{gathered}
0 \leq P_{c h}(t) \leq P_{c h \_ \text {max }} \\
0 \leq P_{d i s}(t) \leq P_{d i s_{-} \max } \\
S O C_{\min } \leq S O C(t) \leq S O C_{\max }
\end{gathered}
$$

where, $P_{c h \text { max }}$ and $P_{\text {dis } \max }$ are the maximum charging and discharging power of energy storage respectively, which are taken as $125 \mathrm{~kW}$ in this paper. $S O C_{\min }$ and $S O C_{\max }$ represent the upper and lower limits of energy storage SOC respectively. This paper uses the particle swarm optimization algorithm mentioned in reference [15] to solve the model.

\subsection{Real Time Control Strategy}

The microgrid system is regulated by energy storage, so the energy storage SOC is used as the basis of distributed generation and load switching in real-time control. In each dispatching cycle, the real-time state of energy storage SOC is read, and the wind and solar power, energy storage, diesel engine and load power are adjusted in real time according to the state of energy storage SOC. In this paper, the energy storage SOC is divided into four key nodes, which are: $S O C_{\min }, S O C_{\text {low }}$, $S O C_{\text {high }}, S O C_{\max }$. During normal operation, SOC fluctuates in the range of $S O C_{\min } \sim S O C_{\max }$.

The schematic diagram of energy storage SOC division section is shown in Figure 2.

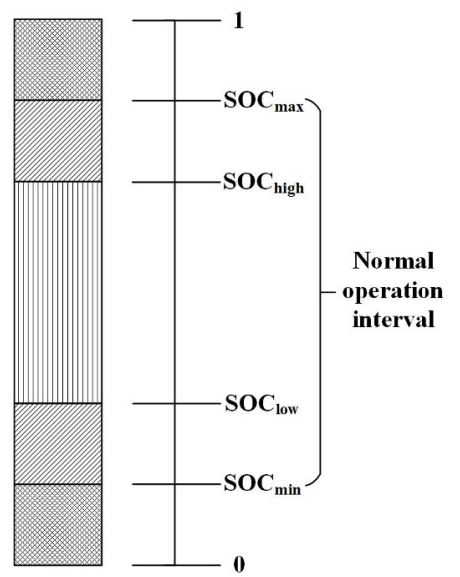

Figure 2 Schematic diagram of energy storage SOC partition

When $S O C>S O C_{\max }$, the battery stops charging.

When $S O C_{\text {high }}<S O C<S O C_{\text {max }}$, the wind and solar power mainly supply the load, if there is power surplus, the energy storage will be charged.

When $S O C_{\text {low }}<S O C<S O C_{\text {high }}$, the wind and solar power mainly supply the load, if there is a power shortage, the energy storage discharge will supplement.

When $S O C_{\text {min }}<S O C<S O C_{\text {low }}$, a certain load is cut off, energy storage is discharged, and the load is supplied together with wind and solar energy.

When $S O C<S O C_{\min }$, put the diesel generator into operation.

In this paper, the values of $S O C_{\text {min }}, S O C_{\text {low }}, S O C_{\text {high }}$, and $S O C_{\max }$ are $0.2,0.4,0.85$ and 0.95 respectively. 


\section{The Example Analysis}

The AC/DC microgrid shown in Figure $\mathbf{1}$ is used for simulation, and the typical environment scenarios of sunny and rainy weather are selected for analysis, and the corresponding dispatching scheme is formulated.

Figure 3 shows the forecast of typical daily wind turbine output based on historical wind speed.

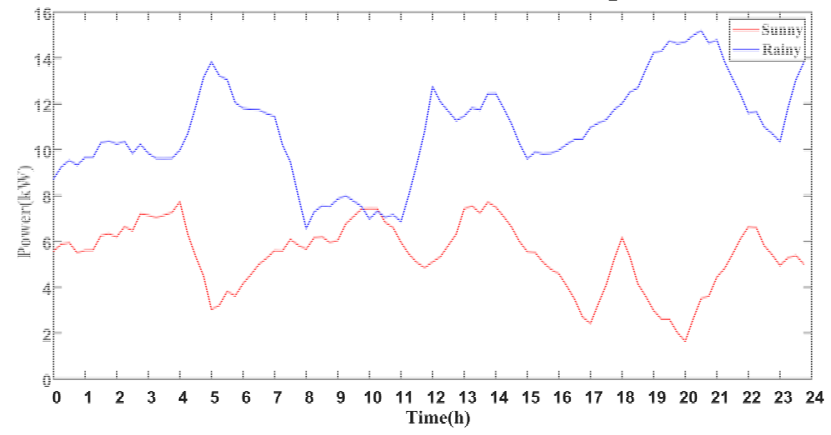

Figure 3 Forecast of wind turbine output power in typical day

Figure 4 shows the forecast of typical daily photovoltaic output based on historical solar radiation intensity.

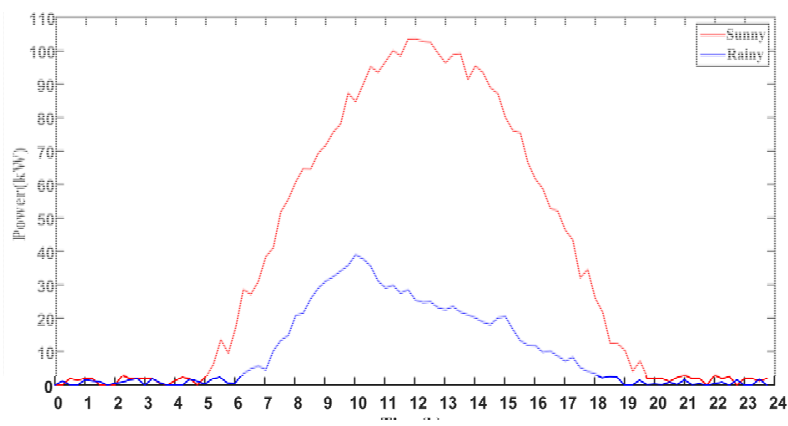

Figure 4 Forecast of photovoltaic output power in typical day

\subsection{Typical Sunny Day Scheduling Results}

Typical sunny day scheduling results are shown in Figure

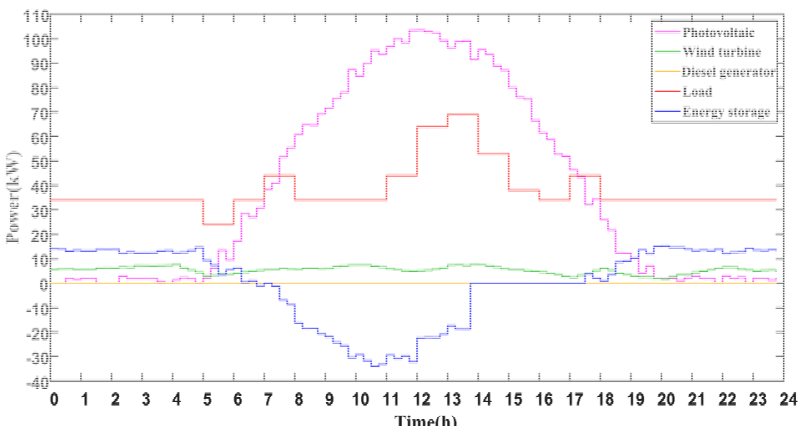

Figure 5 Typical sunny day scheduling results

It can be seen that in sunny days, photovoltaic power generation is the main energy source of the island. In sunny days with abundant light resources, diesel generators do not need to be started. As the electric vehicle charging needs to run at least 12 hours a day, it is set at 6:00-18:00 when the wind and solar resources are sufficient. During the period of 0:00-6:00, the wind and solar resources are poor, the energy storage system discharges and supplies the load electricity together with the wind turbine and photovoltaic. During the period of 6:00-14:00, the light level improves, the wind and solar output is greater than the load demand, the energy storage system charges, the energy storage capacity reaches the upper limit at 13:30, and the charging stops. After 11:00, the load gradually increases, the forestry production electricity will be put into use at 12:00, the meeting room will be put into use at 13:00, and the Class II domestic electricity will be put into use at 14:00. The peak of load electricity is from 13:00-14:00. From 13:30 to $17: 30$, the energy storage is no longer charged, the wind and solar output only supplies the load power, and the excess power will be abandoned. During 17:30-24:00, the light level drops, the wind and solar output power 
cannot continue to meet the load power demand, and the energy storage starts to discharge again.
The SOC curve of single energy storage in typical sunny day is shown in Figure 6.

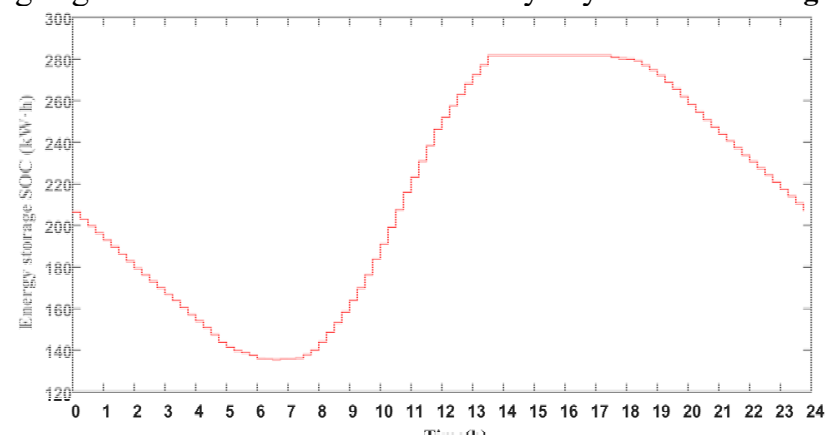

Figure 6 SOC curve of energy storage in typical sunny day

During the period of 0:00-7:00 due to insufficient wind and solar output, energy storage discharges, and the SOC gradually decreases. During the period of 7:0013:40, with the increase of wind and solar output, the SOC gradually increased due to the energy storage charging. During the period of 13:30-17:30, the SOC of energy storage no longer charged, remained unchanged at the level of $S O C_{\max }$. After 17:30, due to the decrease of wind and solar output, the load demand cannot be met, so the energy storage starts to discharge again, and the

SOC gradually decreases. At 24:00, it returns to the initial capacity.

Since the diesel generator has not been started and the Class I domestic electricity has always been maintained at the rated power without reduction, the dispatch cost for a typical sunny day is 0 yuan.

\subsection{Typical Rainy Day Scheduling Results}

Typical rainy day scheduling results are shown in Figure 7.

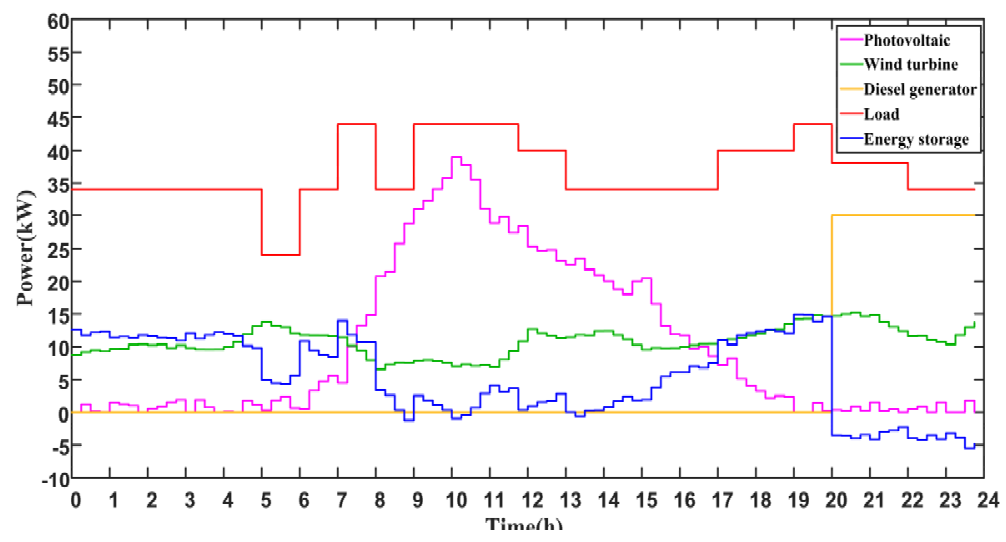

Figure 7 Typical cloudy day scheduling results

In rainy weather with insufficient light resources, since forestry production electricity is restricted by its shiftable time period, it will be put into use in the period (9:00-11:00) with greater wind and solar output. Conference room electricity will be directly cut off. The electric vehicle charging operation period is 6:00-9:00 and 11:00-20:00. In the period of forestry production power input, the electric vehicle charging will stop. Diesel generators will start at 20:00 and keep running at rated power. The peak load is obviously lower than that in sunny weather, and the electricity consumption period is mainly concentrated in 7:00-13:00 and 17:00-22:00. During the period of 0:00-20:00, the energy storage is in the discharge state most of the time, supplying power to the load together with the wind and solar resources, and only a few periods $(8: 45-9: 00,10: 00-10: 30,13: 15-13: 30)$ are in the charging state. Due to the SOC of energy storage dropped below $S O C_{l o w}$, Class I domestic electricity will be reduced to $60 \%$. During the period of 20:00-24:00, the sum of wind and solar power output and diesel power output is greater than the load demand, and the energy storage starts charging.

The SOC curve of typical rainy day is shown in Figure 8 . 


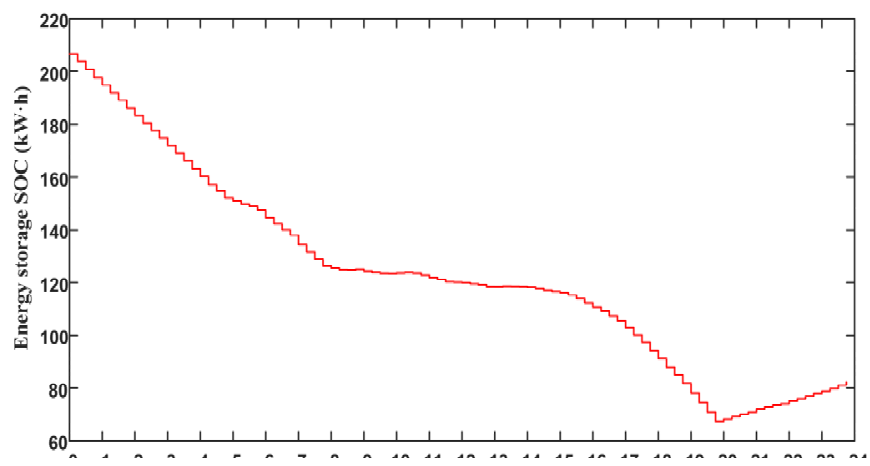

Figure 8 SOC curve of energy storage in typical cloudy day

During the period from 0:00-11:45, the energy storage SOC is between $S O C_{\text {high }}$ and $S O C_{\text {low }}$, and the overall SOC level shows a downward trend, and the wind and solar output mainly supplies power to the load. During the period from 11:45-20:00, the SOC continues to decline, and the energy storage SOC between $S O C_{\text {low }}$ and $S O C_{\min }$, the system will perform load shedding. At 20:00, the energy storage SOC will drop, and the diesel generator will start. As the sum of wind and solar output and diesel generator output is greater than the load demand, the energy storage starts to charge, and the SOC of energy storage reaches about $27 \%$ at $24: 00$.

On a typical rainy day, according to the operation time and output of the diesel generator and the load shedding of the system, the dispatching cost is calculated to be 182.4 yuan.

\section{Conclusion}

This paper proposes a set of power regulation strategy for island independent $\mathrm{AC} / \mathrm{DC}$ hybrid microgrid. Using the combination of day-ahead scheduling and real-time control, the day-ahead scheduling strategy provides a reference for the island's electricity utilization arrangement. The real-time control strategy controls the output of distributed power, the reduction of load and the switching of diesel generators through energy storage SOC. The simulation results show that the proposed method can effectively control the island independent $\mathrm{AC} / \mathrm{DC}$ hybrid microgrid on typical sunny and rainy days, meet the load demand, improve the utilization of renewable resources, reduce the use of diesel generators, and improve the system operation economy and environmental protection.

\section{Acknowledgments}

This work is supported by S\&T Program of Hebei (20312102D).

\section{References}

1. ZHANG J, YU L, LIU N, et al. (2014) Capacity configuration optimization for island microgrid with wind/photovoltaic/diesel/storage and seawater desalination load[J]. Transactions of China Electrotechnical Society, 29(02):102-112.

2. WEI F, SUI Q, LIN X, et al. (2018) Optimized energy control strategy about daily operation of islanded microgrid with wind/photovoltaic/diesel/battery under consideration of transferable load efficiency[J]. Proceedings of the CSEE, 38(04):1045-1053.

3. ZHU Y, JIA L, CAI B, et al. (2016) Overview on topologies and basic control strategies for hybrid AC/DC microgrid[J]. High Voltage Engineering, 42(9):2756-2767.

4. MI Y, SONG G, SONG Y, et al. (2020) Strategy of multi-level power management for islanded AC/DC hybrid microgrid cluster[J]. Automation of Electric Power Systems, 44(07):38-45.

5. EGHTEDARPOUR N, FARJAH E. (2014) Power Control and Management in a Hybrid AC/DC Microgrid[J]. IEEE Transactions on Smart Grid, 5(3):1494-1505.

6. LIN W, MENG X, JIN X, et al. (2018) Unified dayahead scheduling method for distribution network and microgrids considering different entities[J]. Distribution \& Utilization, 2018,35(07):9-12

7. YANG Y, LEI X, YE T, et al. (2014) Microgrid energy optimal dispatch considering the security and reliability $[\mathrm{J}]$. Proceedings of the CSEE, 34(19):3080-3088.

8. NEJABATKHAH F, LI Y W. (2015) Overview of Power Management Strategies of Hybrid AC/DC Microgrid[J]. IEEE Transactions on Power Electronics, 30(12):7072-7089.

9. SUN G, QI C, HAN B, et al. (2016) Research of key technology of $\mathrm{AC} / \mathrm{DC}$ hybrid distribution network planning and operation[J]. Distribution \& Utilization, 35(08):7-17.

10. SAHOO S K, SINHA A K, KISHORE N K. (2018) Control Techniques in AC, DC, and Hybrid AC-DC Microgrid: A Review[J]. IEEE Journal of Emerging and Selected Topics in Power Electronics, 6(2):738759.

11. SHARAFI M, ELMEKKAWY T Y. (2014) A dynamic MOPSO algorithm for multi-objective optimal design of hybrid renewable energy 
systems[J]. International Journal of Energy Research, 38(15):1949-1963.

12. XIE W, LI G, FANG C, et al. (2016) Multi-time scale energy management strategy of microgrid containing sodium sulfur battery energy storage systems[J]. Advances of Power System \& Hydroelectric Engineering, 32(10):160-166.

13. MOKHEIMER E M A, SAHIN A Z, AL-SHARAFI A, et al. (2013) Modeling and optimization of hybrid wind-solar-powered reverse osmosis water desalination system in Saudi Arabia[J]. Energy Conversion and Management, 75:86-97.

14. YUAN Y, LI L. (2019) Optimal operation of energy management for AC/DC hybrid microgrid considering partition demand side management[J]. Power Demand Side Management, 21(03):63-68.

15. LIU J, WANG W, ZHANG G. (2019) Economic operation optimization of island microgrid with seawater desalination system $[\mathrm{J}]$. Electric Power Engineering Technology, 38(06):122-129. 